\title{
Key attributes of patient centered medical homes associated with patient activation of diabetes patients
}

Lori A. Bilello ${ }^{1 *}$ D, Allyson Hall ${ }^{2}$, Jeffrey Harman ${ }^{3}$, Christopher Scuderi ${ }^{4}$, Nipa Shah ${ }^{5}$, Jon C. Mills ${ }^{6}$ and Shenae Samuels ${ }^{7}$

\begin{abstract}
Background: Approximately 24 million Americans are living with diabetes. Patient activation among individuals with diabetes is critical to successful diabetes management. The Patient Centered Medical Home (PCMH) model holds promise for increasing patient activation in managing their health. However, what is not well understood is the extent to which individual components of the PCMH model, such as the quality of physician-patient interactions and organizational features of care, contribute to patient activation. This study's objective is to determine the relative importance of the PCMH constructs or domains to patient activation among individuals living with diabetes.

Methods: This study is a cross-sectional analysis of 1253 primary care patients surveyed with type II diabetes. The dependent variable, patient activation, was assessed using the Patient Activation Measure (PAM). Independent variables included 7 PCMH domains- organizational access, integration of care, comprehensive knowledge, office staff helpfulness, communication, interpersonal treatment and trust. Ordered logistic regression was performed to determine whether each PCMH domain was independently associated with patient activation, followed by a final ordered logistic regression that included all the PCMH domains in a single adjusted model.
\end{abstract}

Results: Using the full adjusted model, the odds of patients reporting higher activation scores (PAM) were found to be significant in the domains that represented organizational access (OR 1.56, 95\% Cl 1.31-1.85) and comprehensive knowledge (OR 1.44, 95\% Cl 1.13-1.85).

Conclusions: Many practices have struggled with the challenge to develop fully functional patient-centered medical homes. In an effort to become more patient-centered, this study aimed to address what factors activated diabetic patients to adhere to diabetes management plan. Understanding these factors can help identify PCMH attributes that practices can prioritize and improve upon to assist their patients in improving health outcomes.

Trial registration: Study was not a clinical trial; therefore it was not registered.

\section{Background}

The Medical Home has emerged as a major organizing construct in the delivery of primary care, having first been recognized by the American Academy of Pediatrics (AAP) in 1967. As the concept has been more fully explored, researched and refined over the last half century, more clearly defined principles and practices have been adopted by key primary care professional societies. It

\footnotetext{
* Correspondence: lori.bilello@jax.ufl.edu

${ }^{1}$ Center for Health Equity and Quality Research, College of Medicine, UF Health Jacksonville, 6th Floor, Tower II, Suite 6015, 580 West 8th Street, T60, Jacksonville, FL 32209, USA

Full list of author information is available at the end of the article
}

wasn't fully recognized by the medical establishment until 2007 when the AAP, American College of Physicians, American Academy of Family Physicians, and the American Osteopathic Society published the Joint Principles for a Patient Centered Medical Home (PCMH). In 2008, the National Committee on Quality Assurance (NCQA) adopted criteria for practice recognition as a $\mathrm{PCMH}$. There are 3 levels of NCQA recognition ranging from level 1 to level 3 and require medical practices to demonstrate that they have met certain criteria for the following standards of care: patient centered access, team based care, population health management, care 
management and support, care coordination and care transitions, performance measurement and quality improvement [1].

Recent studies have provided evidence that PCMHs improve the quality of care, lead to better patient outcomes and experiences with the care process, and reduce emergency department visits and hospitalizations [2-4]. The PCMH model is especially relevant to the care of patients with chronic diseases such as diabetes where it requires close monitoring by the provider, patients involved in the management of their disease, a team-based approach in the continuum of care and adopts many of the components of Wagner's Chronic Care Model [5, 6]. Several of the Centers for Medicare and Medicaid Services' (CMS) funded PCMH demonstration projects have reported improvements in Hemoglobin A1c (HbA1c) control and provide encouraging results to support the PCMH model as a viable mechanism to improve the quality of diabetes care [7].

Patient centered care not only recognizes the patient as central to care provision, but it also requires the patient to be involved in their care and to have the knowledge, skills, and motivation to do so. Promoting patient activation is a key principle in a PCMH setting and is essential to the provision of high quality care and to achieve better patient outcomes. Patient activation is the ability of patients to take a pro-active role in managing their health and have the skills, knowledge, and confidence to do so [8] while patient engagement or motivation are often described as the preliminary steps to patient activation where the patient is involved in learning about their condition and making decisions about their health but may not have taken a pro-active role in managing their health. Research has found that engaged, informed, confident, and skilled patients are more likely to perform activities that will maintain or promote their own health $[9,10]$. A study by Remmers et al. showed that patients with diabetes who are more activated in their care had better HbA1c control and conformed to the diabetes guidelines in testing for HbA1c and LDL Cholesterol [11].

For practices that are adopting the PCMH model, an important consideration is whether certain constructs or domains of the model have a higher likelihood of activating patients relative to other domains. As described in the Engagement Behavior Framework by the Center for Advancing Health, several components related to the patients' clinical care, such as seeking appropriate, high quality care, communication with health professionals and organizational access, are important factors for patient engagement [12]. Understanding the relative importance of these medical home domains to patients can guide practices that are converting to the $\mathrm{PCMH}$ model develop specific strategies to improve patient activation. The goal of this study is to determine the relative importance of certain well-established $\mathrm{PCMH}$ constructs or domains and their association to patient activation among individuals living with diabetes.

\section{Methods}

Patients with diabetes at 4 large family medicine centers were surveyed about their experiences with care and if they took an active role in their health and healthcare. These primary care practices have achieved the highest level of NCQA recognition (Level 3) as a PCMH, are affiliated with an U.S. academic medical center, and participate in a practice based research network in Florida. One practice was located at the academic medical center while the other three practices were located in various sections of a large metropolitan city and had diverse patient populations. There were over 5300 diabetic patients being managed by these 4 practices. Patients who met the inclusion criteria of being 18 years and older with an ICD-9 (International Classification of Diseases-9th Revision) code indicating type II diabetes (codes 250-250.9) who had at least 2 visits within the past 2 years (2012-2013), and who did not opt out were randomly selected to participate in a telephone survey administered by a university based Survey Research Laboratory in 2014. The survey took approximately $10 \mathrm{~min}$ for respondents to complete. A power analysis resulted in needing 1301 participants in order to detect a five point difference in domain ratings across the four clinics with $80 \%$ power. Sampling occurred until 1301 surveys were completed. The actual analytic sample was reduced to 1253 after observations with missing data were excluded with minimal effect on the power. The response rate for each clinic (the number of complete interviews divided by the number of telephone numbers contacted) ranged from 65 to $73 \%$.

The survey instrument included the Patient Activation Measure (PAM) and items from the Ambulatory Care Experiences Survey (ACES). The PAM is widely used to assess the knowledge, skills and confidence of individuals in managing their own health and their healthcare and has been tested to be a reliable and valid tool for patient activation $[8,13]$. Numerous studies have used the PAM tool to assess patient activation in different patient populations such as rural populations, patients with chronic conditions such as diabetes, multiple sclerosis or mental health conditions that have shown that patient activation is positively related to patient self -management [14-18]. Additionally the tool has been translated and validated in other languages included Dutch, German and Danish [19-21].

The ACES instrument includes 11 summary measures of patients' experiences across 2 domains, quality of physician-patient interactions and organizational features of care, and has been extensively tested, validated 
and used in numerous studies [22-24]. Using items from seven of the 11 available measures from ACES, we constructed a shortened version of the survey with the following medical home domains: organizational access, comprehensive knowledge, integration of care, communication, office staff helpfulness, interpersonal treatment, and trust. Items selected from the ACES for each domain are listed in Table 1. The domains that were selected best fit the organizational structure of the PCMHs included in the study. The PCMH domains of organizational access, communication, integration of care and comprehensive knowledge are composite measures while office staff helpfulness, interpersonal treatment and trust are single item measures. The composites were developed based on scoring instructions provided by the ACES developers. The instructions provided by the developers pertained to a more comprehensive version of the ACES survey called the Primary Care Assessment Survey. The composite measures were tested for internal consistency and resulted in the following Cronbachs $\alpha$ scores: organizational access (0.86), comprehensive knowledge (0.76), integration and care coordination (0.65), and communication (0.86). Composite measures reflected the mean of the non-missing responses from each item. If the respondent did not provide at least one response to an item within a domain then the observation was considered missing. We dichotomized all composite scores into binary variables to simplify interpretation of the results. We established the threshold of 4.5 based on distributional analysis of the original scores and conducted multiple sensitivity analyses to determine the impact of various thresholds on the outcomes. Sensitivity analysis produced similar results across different thresholds. Observations with a score of 4.5 (mean score for composites) or greater were coded as 1 (a high perception of that PCMH domain) and those below were coded as a 0 (a low perception of that PCMH domain).

\section{Analytic variables}

The Patient Activation Measure (PAM) was used to assess the level of patient activation. PAM scores were on a 0 to 100 scale and converted into an ordinal categorical variable with four levels based on the PAM developers' recommendations: 0 to $47 ; 47.1$ to $55 ; 55.1$ to 67 ; and over 67 .

Covariates/socio-demographic variables were collected from questions in the ACES survey and included age; race (minority, non-minority); gender (female, male); health status (low, medium, high); education (less than high school, high school grad or higher); type of insurance (uninsured, Medicare, private, unknown); marital status (not married, married), and PCMH where the individual was a patient.

Data preparation was performed using Statistical Analysis Software (SAS), Version 9.3 and because the PAM scores were divided into 4 ordered categories, ordered
Table 1 Survey questions from the Ambulatory Care Experiences Survey grouped by PCMH Domains

\begin{tabular}{|c|c|}
\hline PCMH domains & Survey questions \\
\hline \multirow[t]{4}{*}{ Organizational Access } & $\begin{array}{l}\text { When you needed care for an illness or } \\
\text { injury how often did your personal } \\
\text { doctor's office provide care as soon as } \\
\text { you needed it? }\end{array}$ \\
\hline & $\begin{array}{l}\text { When you scheduled an appointment } \\
\text { for a check-up or routine care how often } \\
\text { did you get the appointment as soon as } \\
\text { you needed it? }\end{array}$ \\
\hline & $\begin{array}{l}\text { When you called your personal doctor's } \\
\text { office with a medical question during } \\
\text { regular office hours how often did you } \\
\text { get an answer the same day? }\end{array}$ \\
\hline & $\begin{array}{l}\text { When you called your personal doctor's } \\
\text { office after regular office hours, how } \\
\text { often did you get the help or advice } \\
\text { you needed? }\end{array}$ \\
\hline
\end{tabular}

Integration of Care When your personal doctor sent you for a blood test, $x$-ray, or other tests, did someone from your doctor's office follow-up to give you the test results?

How often did your personal doctor seem informed and up to date about the care your received from your specialist doctor?

Comprehensive Knowledge How would you rate your doctor's knowledge of your medical history?

In the last 12 months, how often did your doctor seem to know all the important information about your medical history?

Office Staff Helpfulness In the last 12 months, how often were the office staff at your personal doctor's office HELPFUL as you thought they should be?

Communication How often did your personal doctor listen carefully to you?

How often did your personal doctor give you clear instructions about what to do to take care of the health problems and symptoms that were bothering you?

How often did your personal doctor explain things in a way that was easy to understand?

Interpersonal Treatment How often did your personal doctor spend enough time with you?

Trust How often did you feel you could tell your personal doctor anything, even things you might not tell anyone else?

Adapted from Safran DG et al. [22]

PCMH Patient Centered Medical Home

logistic regression analyses was performed using STATA SE, Version 13.1. We first modeled each PCMH domain separately (adjusted for covariates). This was done in order to determine whether each PCMH domain was independently associated with patient activation. Then we performed one final ordered logistic regression that included 
all the PCMH domains in a single adjusted model using the ordered logit procedure in STATA with PAM (4 ordered categories) as the dependent variable. Since patients were sampled within physician practices, we used random effects to account for correlation of patients due to clinical practice characteristics.

\section{Results}

The study sample, which includes patients with diabetes at the 4 PCMHs participating in the study, is representative of an urban population. The majority of participants consider themselves to be a racial or ethnic minority, with only $37.4 \%$ identifying as non-Hispanic white. The average age was $60.9 \pm 11.61$ with a range of 19 to 89 years. Other demographic characteristics include: $74.1 \%$ reported having a high school education/ GED or higher, $41.6 \%$ were married, and $10.6 \%$ considered themselves to have low health status. Medicare was the most common insurance coverage (44.8\%) followed by Medicaid/uninsured (28.2\%) and private insurance $(27.0 \%)$. Many of the patients have been receiving care from the same medical practice for 3 years or more $(62.9 \%)$. See Table 2 for details of the study sample characteristics.

Table 3 shows the results from the ordered logit models showing the relationship between each PCMH domain individually and PAM scores. The odds of patients reporting higher activation scores (PAM) were found to be significant for each of the PCMH domains: organizational access (OR 2.35, 95\% CI 1.89-2.92), integration of care (OR 2.09, 95\% CI 1.91-2.28), comprehensive knowledge (OR 2.90, 95\% CI 1.07-4.04), office staff helpfulness (OR 2.50, 95\% CI 1.70-3.67), communications (OR 3.27, 95\% CI 2.943.63), interpersonal treatment (OR 2.32, 95\% CI 1.613.34) and trust (OR 2.67, 95\% CI 2.09-3.65).

Table 4 shows the results from the ordered logit model that included all PCMH domains and covariates in one model. The odds of patients reporting higher activation scores (PAM) were found to be significant for only two of the PCMH domains: organizational access (OR 1.56, 95\% CI 1.31-1.85) and comprehensive knowledge (OR 1.44, 95\% CI 1.13-1.85). Patients in excellent health or good health were more likely to have higher activation scores compared to those who self-rated their health as fair or poor. In addition, our analysis found that individuals who were high-school graduates and were white (non-Hispanic) had higher odds of having a higher PAM score, compared to individuals who were not high-school graduates. Also, as age increases the likelihood of having a higher activation score declined.

\section{Discussion}

Many practices have struggled with the challenge to develop fully functional patient-centered medical homes. In
Table 2 Sample Characteristics $(n=1253)$

\begin{tabular}{ll}
\hline & Percent \\
\hline Length of time with Provider & \\
Less than 6 months & 8.16 \\
Between 6 months - less than 1 year & 7.76 \\
1 year to less than 3 years & 21.21 \\
3 years but less than 5 years & 16.14 \\
5 years or more & 46.73 \\
Gender & \\
Male & 35.51 \\
Female & 64.49 \\
Education & \\
High School diploma or more & 74.14 \\
No High School diploma & 25.86 \\
Health Status & \\
Excellent/Nery Good & 19.06 \\
Good & 35.57 \\
Fair/Poor & 45.37 \\
Race/Ethnicity & \\
White non-Hispanic & \\
Minority & \\
Marital Status & \\
Not married & \\
Medican & \\
\hline
\end{tabular}

an effort to become more patient-centered, this study aimed to address what factors motivated diabetic patients. Understanding these factors can help identify areas of the PCMH model that practices can prioritize to emphasize patient activation. This study suggests that patients' perceptions regarding ready access to their doctor (organizational access) and their doctor's knowledge of their medical history (comprehensive knowledge), are important factors in motivating patients to take an active role in their health and healthcare. These findings are consistent with previous studies $[25,26]$ that showed modest improvement in patient activation in PCMH settings, especially in minority patients [25]; however, other similar studies show mixed results $[3,27]$. Overall, there have been very few studies that has examined how the PCMH organizing model motivates patients to be more active in their healthcare.

Results of the study suggest that patients value their doctor's comprehensive knowledge of their medical 
Table 3 Relationship between each individual PCMH domain and likelihood of higher activation score

\begin{tabular}{lllll}
\hline PCMH domain & Odds ratio & \multicolumn{2}{l}{$95 \%$ Confidence interval } & Upper bound \\
\cline { 3 - 4 } & & Lower bound & 3.21 & .000 \\
\hline Organizational Access & 2.54 & 2.02 & 2.69 & .000 \\
Integration of Care & 2.26 & 1.89 & 4.04 & .000 \\
Comprehensive Knowledge & 2.91 & 2.10 & 4.15 & .000 \\
Office Staff Helpfulness & 2.70 & 1.76 & 3.92 & .000 \\
Communication & 3.21 & 2.63 & 4.03 & .000 \\
Interpersonal Treatment & 2.48 & 1.52 & 3.56 & .000 \\
Trust & 2.68 & 2.02 &
\end{tabular}

Adjusted for: insurance status, age, gender, self-reported health status, racial/ethnic minority status, marital status, length of time with primary care provider (Ordered logit, $n=1253$ )

Table 4 Predictors of higher activation score (Ordered logit, $n=1253$ )

\begin{tabular}{|c|c|c|c|c|}
\hline & \multirow[t]{2}{*}{ Odds ratio } & \multicolumn{2}{|c|}{$\underline{95 \% \text { Confidence interval }}$} & \multirow[t]{2}{*}{$p$-value } \\
\hline & & Lower bound & Upper bound & \\
\hline \multicolumn{5}{|l|}{ PCMH domains } \\
\hline Organizational Access & 1.56 & 1.31 & 1.85 & .000 \\
\hline Integration of Care & 1.14 & 0.93 & 1.41 & .197 \\
\hline Comprehensive Knowledge & 1.44 & 1.13 & 1.83 & .003 \\
\hline Office Staff Helpfulness & 1.37 & 0.86 & 2.19 & .186 \\
\hline Communication & 1.34 & 0.76 & 2.38 & .310 \\
\hline Interpersonal Treatment & 0.92 & 0.43 & 1.97 & .838 \\
\hline Trust & 1.43 & 0.94 & 2.18 & .092 \\
\hline \multicolumn{5}{|c|}{ Length of Time with Provider (Less than 6 months) } \\
\hline Between 6 months - less than 1 year & 0.47 & 0.31 & 0.72 & .001 \\
\hline 1 year to less than 3 years & 1.23 & 1.02 & 1.49 & .024 \\
\hline 3 years but less than 5 years & 1.08 & 0.98 & 1.19 & .110 \\
\hline 5 years or more & 1.37 & 0.92 & 2.03 & .112 \\
\hline \multicolumn{5}{|l|}{ Gender (Female) } \\
\hline Male & 1.00 & 0.84 & 1.19 & .990 \\
\hline \multicolumn{5}{|l|}{ Education (Did not graduate high school) } \\
\hline High school graduate or more & 1.34 & 1.05 & 1.71 & .016 \\
\hline \multicolumn{5}{|l|}{ Health Status (Fair/Poor) } \\
\hline Excellent/Nery Good & 2.57 & 2.21 & 2.99 & .000 \\
\hline Good & 1.50 & 1.08 & 2.07 & .014 \\
\hline \multicolumn{5}{|l|}{ Race/ethnicity (Minority) } \\
\hline White, non-Hispanic & 1.11 & 1.05 & 1.16 & .000 \\
\hline \multicolumn{5}{|l|}{ Marital Status (Not married) } \\
\hline Married & 0.93 & 0.74 & 1.17 & .559 \\
\hline \multicolumn{5}{|l|}{ Insurance Type (Medicaid/uninsured) } \\
\hline Private & 1.40 & 1.23 & 1.57 & .000 \\
\hline Medicare & 1.11 & 0.97 & 1.30 & .133 \\
\hline Age & 0.98 & 0.96 & 0.99 & .002 \\
\hline
\end{tabular}


history; perhaps allowing patients to feel more confident and hence, trusting that their doctor is competent in delivering the best care based on their medical history and overall needs. Physicians/providers comprehensive knowledge of their patients' health issues and life circumstances may lead to a more personalized care plan that meets the needs of the patient and takes into consideration their current level of selfmanagement skills and resources available to them. Organizational access was also found to be an important factor in patient activation. Study results indicate that patients value the ability to quickly receive care and/or appointments. Similar to the aforementioned domains, office staff helpfulness and communication may also play a vital role in contributing to trust as patients are more likely to adhere to treatment when their doctor is able to give clear instructions and explanations, listens carefully and has a helpful office staff.

Unexpectedly, the results showed that interpersonal treatment was not associated with greater patient activation when we control for other PCMH characteristics. The survey question that is related to this domain asked how often their doctor spent enough time with them. Several studies have shown that patient satisfaction is linked to the patient's perceived adequacy of the length of time they spend with their physician [28-30]. This result suggests that the time spent with the physician may not activate the patient as much as the quality of the time spent with the patient or other factors related to their office visit. The domains communication, office staff helpfulness, integration of care, interpersonal treatment, and trust became insignificant after controlling for other PCMH domain scores. This may be due to some overlapping concepts of these domains. In addition, the original ACES survey had at least 2 items for the office staff helpfulness, interpersonal treatment and trust domains and reducing these domains to a single item may impact the strength of their psychometric property.

It is important to note that this study has some limitations. First, it is a cross-sectional study, so we are unable to determine causality and the direction of the relationship between $\mathrm{PCMH}$ rating and patient activation. It is possible that more activated patients seek out well functioning medical practices or PCMHs. However, the family practice centers that participated in this study do not advertise themselves as PCMHs and each has a different population they serve (from inner city to suburbia) which is a strength of this study. Additionally, patients can chose their primary care doctor but there choice is usually limited by their insurance plans' networks of participating physicians.

Our analysis did not collect data on the participants' diabetes history, A1c levels, current treatments, or diabetes-related complications. This limitation did not allow us to determine if any of these factors may have an impact on patient activation. Another limitation of the study is that participating practices were located in a single state and were affiliated with a single academic medical center, potentially reducing generalizability. Furthermore, due to the lack of availability of electronic clinical data prior to the implementation of the electronic medical record (EMR), the authors were unable to compare pre vs. post assessment of medical home adoption. Future research should investigate, using a pre-post assessment, the impact of medical home adoption on patient activation and how improvements in each domain increases patient activation. Nevertheless, these findings have important implications regarding the adoption of PCMH concepts and practices and the need to improve organizational access and comprehensive knowledge of patients' conditions to assist patients in having a more active role in their health and healthcare.

\section{Conclusions}

Findings from this study contribute to an area of PCMH research that remains relatively unexplored; that is, whether or not certain attributes of medical homes are linked to levels of patient activation and ultimately better health outcomes. These findings may provide insights on the mechanism through which patients may play a more active role in their health and healthcare and hence, an increased likelihood of treatment adherence. If efforts to transform the primary care delivery system are to succeed, understanding key practice characteristics that might achieve improvements in patient activation has implications on how the PCMH model is operationalized and implemented moving forward. The development and implementation of practice strategies that improve access and providers understanding of patients' needs can be tested and monitored using the PAM to measure improvements in patient activation. As such, findings of this study as well as future studies addressing specific strategies as noted above may inform policymakers as they advocate policies that facilitate primary care practices to transform into PCMHs.

\section{Abbreviations}

ACES: Ambulatory Care Experiences Survey; EMR: Electronic medical record; NCQA: National Committee on Quality Assurance; PAM: Patient Activation Measure; PCMH: Patient Centered Medical Home

\section{Acknowledgements}

We gratefully acknowledge the members of the primary care practices who participated in this study.

\section{Funding}

This project was supported by a grant from The Aetna Foundation, a national foundation based in Hartford, Connecticut that supports projects to 
promote wellness, health and access to high-quality health care for everyone. The foundation had no role in the design of the study and collection, analysis, and interpretation of data and in writing the manuscript. The views presented here are those of the authors and not necessarily those of those of The Aetna Foundation, its directors, officers, or staff.

\section{Availability of data and materials}

The datasets during and/or analyzed during the current study available from the corresponding author on reasonable request.

\section{Authors' contributions}

$\mathrm{AH}$ conceived of the study and was the Principal Investigator of the study. LB provided data analysis and drafted the manuscript. JH participated in the conception of the study, study design and participated in the analysis. CS and NS provided oversight of the implementation of the study at the primary care practices and data collection. JM and SS assisted in the data analysis. All authors participated in the drafting of the article and have read and approved the final manuscript.

\section{Ethics approval and consent to participate}

Ethics approval was provided by the University of Florida Institutional Review Board - IRB01 (expedited approval \#18-2012). Survey participation was voluntary and patients had the choice of opting out of the study.

\section{Consent for publication}

Not applicable.

\section{Competing interests}

The authors declare that they have no competing interests.

\section{Publisher's Note}

Springer Nature remains neutral with regard to jurisdictional claims in published maps and institutional affiliations.

\section{Author details}

${ }^{1}$ Center for Health Equity and Quality Research, College of Medicine, UF Health Jacksonville, 6th Floor, Tower II, Suite 6015, 580 West 8th Street, T60, Jacksonville, FL 32209, USA. ²Department of Health Services Administration, School of Health Professions, University of Alabama at Birmingham, 1720 2nd Ave S, Birmingham, AL, USA. ${ }^{3}$ Department of Behavioral Sciences and Social Medicine, College of Medicine, Florida State University, 1115 West Call Street, Tallahassee, FL 32306, USA. " Department of Community Health and Family Medicine, UF Health Family Medicine and Pediatrics - New Berlin, 3122 New Berlin Road, Jacksonville, FL 32226, USA. ${ }^{5}$ Department of Community Health and Family Medicine, College of Medicine, UF Health Jacksonville, 3rd Floor LRC, 653-1 West 8th Street, C257, Jacksonville, FL 32209, USA. 'Department of Epidemiology, College of Medicine, University of North Carolina - Chapel Hill, 2103B, 135 Dauer Drive, Chapel Hill, NC 27599, USA. ${ }^{7}$ Department of Health Services Research, Management \& Policy, College of Public Health and Health Professions, University of Florida, PO Box 100195, Gainesville, FL 32610, USA.

\section{Received: 7 July 2017 Accepted: 20 December 2017}

\section{Published online: 05 January 2018}

\section{References}

1. National Committee on Quality Assurance. Patient-centered medical home. 2014. http://www.ncqa.org/Portals/0/Programs/Recognition/PCMH/PCMH2014_Brochure-web-1.pdf. Accessed 2 Dec 2015.

2. Nielsen M, Langner B, Zema C, Hacker T, and Grundy P. Benefits of implementing the primary care patient-centered medical home: a review of cost \& quality results, patient-centered primary care collaborative. 2012. https://www.pcpcc.org/guide/benefits-implementing-primary-care-medicalhome. Accessed 20 Dec 2015.

3. Jaén $C R$, Ferrer RL, Miller WL, et al. Patient outcomes at 26 months in the patient-centered medical home national demonstration project. Ann Fam Med. 2010;8(suppl 1):S57-S67; S92. doi: https://doi.org/10.1370/afm.1121.

4. Maeng DD, Graf TR, Davis DE, Tomcavage J, Bloom FJ Jr. Can a patientcentered medical home lead to better patient outcomes? The quality implications of Geisinger's ProvenHealth Navigator. Am J Med Qual. 2012;27: 210-6. doi: https://doi.org/10.1177/1062860611417421.
5. Bodenheimer T, Wagner EH, Grumbach K. Improving primary care for patients with chronic illness: the chronic care model, part 2. JAMA. 2002; 288(15):1909-14.

6. Wagner EH. Chronic disease management: what will it take to improve care for chronic illness? Eff Clin Pract. 1998;1:2-4.

7. Bojadzievski T, Gabbay RA. Patient-centered medical home and diabetes. Diabetes Care. 2011;34:1047-53. doi: https://doi.org/10.2337/dc10-1671.

8. Hibbard JH, Stockard J, Mahoney ER, Tusler M. Development of the Patient Activation Measure (PAM): conceptualizing and measuring activation in patients and consumers. Health Serv Res. 2004;39(4):1005-10026. doi: https://doi.org/10.1111/j.1475-6773.2004.00269.x.

9. Mosen DM, Schmittdiel J, Hibbard J, Sobel D, Remmer C, Bellows J. Is patient activation associated with outcomes of care for adults with chronic conditions? J Ambul Care Manage. 2007;30(1):21-9.

10. Von Korff M, Gruman J, Schaefer J, Curry SJ, Wagner EH. Collaborative management of chronic illness. Ann Intern Med. 1997;127:1097-102.

11. Remmers C, Hibbard J, Mosen DM, Wagenfield M, Hoye RE, Jones C. Is patient activation associated with future health outcomes and healthcare utilization among patients with diabetes? J Ambul Care Manage. 2009;32(4):1-8. doi: https://doi.org/10.1097/JAC.0b013e3181ba6e77.

12. Center for Advancing Health. 2010. "A new definition of patient engagement: what is engagement and why is it important?". Available at http://www.cfah.org/pdfs/CFAH_Engagement_Behavior_Framework_current. pdf. Accessed 15 June 2017.

13. Hibbard JH, Mahoney ER, Stockard J, Tusler M. Development and testing of a short form of the patient activation measure. Health Serv Res. 2005;40: 1918-30. doi: https://doi.org/10.1111/j.1475-6773.2005.00438.x.

14. Hung M, Carter M, Hayden C, et al. Psychometric assessment of the patient activation measure short form (PAM-13) in rural settings. Qual Life Res. 2013; 22:521. https://doi.org/10.1007/s11136-012-0168-9

15. Green CA, Perrin NA, Polen MR, Leo MC, Hibbard JH, Tusler M. Development of the patient activation measure for mental health. Admin Pol Ment Health. 2010;37(4):327-33.

16. Skolasky RL, Green AF, Scharfstein D, Boult C, Reider L, Wegener ST. Psychometric properties of the patient activation measure among multimorbid older adults. Health Serv Res. 2011;46(2):457-78. doi: https:// doi.org/10.1111/j.1475-6773.2010.01210.x.

17. Stepleman L, Rutter MC, Hibbard J, Johns L, Wright D, Hughes M. Validation of the patient activation measure in a multiple sclerosis clinic sample and implications for care. Disabil Rehabil. 2010;32(19):1558-67.

18. Rask KJ, Ziemer DC, Kohler SA, Hawley JN, Arinde FJ, Barnes C. Patient activation is associated with healthy behaviours and ease in managing diabetes in an indigenous population. Diabetes Educ. 2009; 35:622-10.1177/0145721709335004.

19. Maindal HT, Sokolowski I, Versted P. Translation, adaptation and validation of the American short form Patient Activation Measure (PAM 13) in a Danish version. BMC Public Health. 2009;9:209. doi: https://doi.org/10.1186/ 1471-2458-9-209.

20. Rademakers J, Nijman J, van der Hoek L, Heijmans M, Rijken M. Measuring patient activation in the Netherlands: translation and validation of the American short form patient activation measure (PAM13). BMC Public Health. 2012;12(1):577. doi: https://doi.org/10.1186/1471-2458-12-577.

21. Zill JM, Dwinger S, Kriston L, Rohenkohl A, Härter M, Dirmaier J. Psychometric evaluation of the German version of the patient activation measure (PAM13). BMC Public Health. 2013;13:1027. doi: https://doi.org/10. 1186/1471-2458-13-1027

22. Safran DG, Karp M, Coltin $K$, et al. Measuring patients' experiences with individual primary care physicians. Results of a statewide demonstration project. J Gen Intern Med. 2006;21:13-21. doi: https://doi.org/10.1111/j.1525-1497.2005.00311.x.

23. Rodriguez HP, Rogers WH, Marshall RE, Safran DG. The effects of primary care physician visit continuity on patients' experiences with care. J Gen Intern Med. 2007;22:787-93. doi: https://doi.org/10.1007/s11606-007-0182-8.

24. Rodriguez HP, von Glahn T, Grembowski DE, Rogers WH, Safran DG. Physician effects on racial and ethnic disparities in patients' experiences of primary care. J Gen Intern Med. 2008;23:1666-72. doi: https://doi.org/ 10.1007/s11606-008-0732-8.

25. Nocon RS, Gao Y, Gunter KE, Jin J, Casalino LP, Quinn MT, Derrett S, Summerfelt WT, Huang ES, Lee SM, Chin MH. Associations between medical home characteristics and support for patient activation in the safety net: understanding differences by race, ethnicity, and health status. Med Care. 2014;52(11 Suppl 4):S48-55. 
26. Reid RJ, Coleman K, Johnson EA, et al. The group health medical home at year two: cost savings, higher patient satisfaction, and less burnout for providers. Health Aff (Millwood). 2010;29(5):835-43.

27. Martsolf GR, Alexander JA, Shi Y, et al. The patient-centered medical home and patient experience. Health Serv Res. 2012;47(6):2273-95.

28. Lin C, Albertson GA, Schilling LM, Cyran EM, Anderson SN, Ware L, Anderson RJ. Is Patients' perception of time spent with the physician a determinant of ambulatory patient satisfaction? Arch Intern Med. 2001;161(11):1437-42.

29. Camacho F, Anderson RT, Safrit A, Jones AS, Hoffmann P. The relationship between patient's perceived waiting time and office-based practice satisfaction. NC Med J. 2006;67:409-13.

30. Anderson RT, Camacho FT, Balkrishnan R. Willing to wait? The influence of patient wait-time on satisfaction with primary care. BMC Health Serv Res. 2007;7:31. doi: https://doi.org/10.1186/1472-6963-7-31.

Submit your next manuscript to BioMed Central and we will help you at every step:

- We accept pre-submission inquiries

- Our selector tool helps you to find the most relevant journal

- We provide round the clock customer support

- Convenient online submission

- Thorough peer review

- Inclusion in PubMed and all major indexing services

- Maximum visibility for your research

Submit your manuscript at www.biomedcentral.com/submit
Biomed Central 